application. It appears to me to be especially efficacious, either alone or combined with the bichloride of mercury or the chloride of zinc, in certain forms of soft chancre.

The most striking result, however, is obtained by injecting the solution of quinine into the bladder in those cases where the urine is loaded with pus, and is intensely offensive; the bladder being irritable, the desire to urinate recurring every hour, or more often, for example, where the bladder only imperfectly empties itself, or when the continual use of the catheter is called for in enlarced prostate, or in atony of the organ. Within the past few days I have becn informed by a patient who has habitually had recourse to the catheter, the urine voided being alkaline and highly offensive, that the injection of the quinine solution has been followed by such an abatement of the sensitiveness of the neck of the bladder that the desire to micturate comes on now only after the lapse of six or seven hours, in place of after the lapse of every hour or hour and a half.

The following is the method of using the quinine as a bladder injection :-Dissolve twenty grains of disulphate of guinine in twenty-five ounces of water by the aid of a few drops of dilute sulphuric acid or a teaspoonful of common brown vinegar. Of this solution inject into the bladder two or three ounces, and let it remain.

Stratford-place, $\mathbf{w}$.

\section{A REMARKABLE CASE OF ELEPHANTIASTS ARABUM.}

BY HENRY BLANC, M.D.

SEYIOR SURGEON TO SIR JAMSETJEE JEEJEEBHOY HOSPITAL, AND PROFESSOR OF SURGERY OF THE GRANT MEDICAI COLLEGE, BOMBAY.

P. B-_ a mulatto, a cross between a Portuguese and an African, aged forty-eight; was born and has always resided in Bombay; by occupation a domestic servant. $\mathrm{He}$ states that the disease is of twenty years' duration. It commenced with fever, preceded by chills and rigors, and accompanied with tenderness of the inguinal glands in the groins, and numbness and swelling of the lower extremities. The fever subsided with profuse perspiration, and the swelling in the groins and of the limbs, after an attack, disappeared usually on the third day. He felt a dull pain at first in the right leg and observed that it gradually enlarged until it attained, within three years, its present size. During this period, the patient suffered from occasional attacks of fever, which invariably subsided on the third day. At the commencement of the fifth year since the outset of the disease, he was attacked with fever, accompanied by inflammation of the incinual glands in the left groin ; and the fever, as before, after having run its course for three days, left him. After that he began to experience a dull pain in the left leg, which gradually enlarged, as the right had done, and within four years it attained its present condition. Even now he is subject to occasional attacks of fever, attended by pain and tension, and followed by increase in size of the limbs. His mother had elephantiasis Arabum, but of the rioht leg only, and not to a considerable extent. There is no history of syphilis, intemperance, or of any constitutional disease.

The patient is in a fair condition of body and health. The upper extremities are well formed and present no deformity. The trunk is proportionately built. The inguinal glands are slightly enlarged, painless, and firm on pressure. Temperature in axilla, $98.6^{\circ} \mathrm{F}$.; pulse is of good volume, and 72 per minute. The legs and feet are enormous. Their integument is much hypertrophied, and thrown into folds. These folds look like tumours of different sizes, the largest as big as a cocoa-nut, and are chiefly seen on the outer and posterior aspect of the legs. The smaller tumours are found in abundance on the metatarso-phalanoeal articulations, and are of the size of a small playing marble. The papillæ of the skin over them are thiekened and enlarged, and look like small thorns. From the knees below to about the middle of the legs there is diminished sensibility, but below this, especially on the large tumours, there is complete anæsthesia. The soles of the feet are normally sensitive. The integument over the large tumours is hard, thickened, tough, and covered with dry scales, and is with difficulty pierced with a pin. From the puncture, three-quarters of an inch in depth before any sensation is obtained, there exudes a little thin dark-coloured blood. This blood tunder the microscope presents a large number of broken-down blood-discs, and a few white and a very few red blood-corpuscles held in rouleaux. The circulatory, respiratory; digestive, and urinary organs are normal, and their secretion healthy, and the functions of the skin, apart from that of the lower extremities, are performed normally.

Measurements taken around the legs and feet :-

$\begin{array}{llllll} & & & \text { Right leg. } & \text { Left leg. } \\ \text { Upper fourth } & \ldots & \ldots & 16 \text { in. } & \ldots & 191 \text { in. } \\ \text { Middle } & \ldots & \ldots & 22 \frac{1}{4} \mathrm{in} . & \ldots & 27 \mathrm{in} . \\ \text { Lower fourth } & \ldots & \ldots & 22 \mathrm{in} . & \ldots & 26 \mathrm{in} . \\ \text { The ankle-joint } & \ldots & \ldots & 20 \frac{1}{2} \mathrm{in} . & \ldots & 21 \mathrm{in.}\end{array}$

Tarso-metatarsal articulations

Metatarso-phalangeal articulations

$15 \frac{1}{2}$ in. $\quad \ldots \quad 17$ in.

Bombay.

138 in. $\quad \ldots \quad 14 \frac{1}{4}$ in.

\section{NOTE ON SOUTHEY'S HYPODERMIC DRAINAGE CANNULAE.}

BY J. HOPKINS WALTERS, M.R.C.S.E.

Dr. REgINALD SOUTHEY, in his kind reply to a letter of inquiry respecting this apparatus, wrote me-" $I$ wish some of the several correspondents who write to me personally would detail their own experience with my small instrument to the Clinical Society or the journals. I desire that all the drawbacks as well as the advantages of this procedure should be fairly published." In compliance with this request, I have much pleasure in recording $m y$ first trial of this beantiful little instrument.

My patient, M. S_ a girl aged seventeen, a deaf-mute, was slowly dying of heart failure. She had acute rheumatism with severe cardiac complication fifteen months previously, resulting in mitral insufficiency, enormous dilatation with hypertrophy, and general dropsy. The use of the instrument was delayed, owing to the parents' unwillingmess that the poor girl should be tortured by any operative measure; and it was not until there were considerable ascites and pain, much puffiness of face and body, great swelling of the legs, and a dusky appearance of the skin of the dorsum of each foot, threatening gangrene, that they acceded to my wish and her piteous appeal that something might be done for her. Accordingly (Aug. 3r', 1877) I introduced beneath the skin of the dorsum of the right foot a cannula, and attached to it about a yard of the fine tubing provided for the purpose of conducting the serum into a vessel beside the bed. During the first twenty-four hours two quarts of fluid were abstracted, cansing considerable diminution of the circumference of the leg. At the end of this period no redness was apparent at the site of puncture, so the cannula was left in. She had several attacks of syncope through sitting up, but was very comfortable when recumbent, and her pulse was less intermittent. She insisted on a second cannula being introduced, and 1 therefore (Aug. 4th), with some reluctance, inserted one into the dorsum of the left foot. During the next twenty-four hours two more quarts were passed through the two tubes, making one gallon of serum in forty-eight hours, lessening the general anasarea and reducing the size of the legs by one-half. In the night the tube first used slipped out during movement, but was replaced by the patient herself without difficulty or pain. A little redness appeared round the cannula in the right foot, so I withdrew both, and (Aug: 5th) inserted a clean cannula beneath the skin of each leg above the ankle, and, to prevent them from slipping out, put a narrow strip of strapping across the end of the cannula holding the india-rubber tube. No cradle was used over the legs, owing to the difficulty of keeping them warm. The drainage through the cannulre continued, although not in anything like the same quantity, and could not be estimated owing to leakage from the first-made punctures in the feet. These assumed an angry, and proceeded to a gangrenous, appearance; but a wound at each place, the size of a sixpence, resulted, and quickly took on a healthy action and began to heal. No inflammation occurred at the sites of the cannulx introduced on the 5th, and which remained in for twenty. 